\title{
Chromium Picolinate Intake and Risk of Type 2 Diabetes: An Evidence-Based Review by the United States Food and Drug Administration
}

\author{
Paula R. Trumbo, PhD, and Kathleen C. Ellwood, PhD
}

The labeling of both health claims that meet significant scientific agreement (SSA) and qualified health claims on conventional foods and dietary supplements requires pre-market approval by the US Food and Drug Administration (FDA). Approval by the FDA involves, in part, a thorough review of the scientific evidence to support an SSA or a qualified health claim. This article discusses FDA's evidence-based review of the scientific evidence on the role of chromium picolinate supplements in reducing the risk of type 2 diabetes. Based on this evidence-based review, FDA issued a letter of enforcement discretion for one qualified health claim on chromium picolinate and risk of insulin resistance, a surrogate endpoint for type 2 diabetes. The agency concluded that the relationship between chromium picolinate intake and insulin resistance is highly uncertain.

(c) 2006 International Life Sciences Institute

doi: 10.1301/nr.2006.aug.357-363

Key words: chromium picolinate, diabetes, health claims, type 2 diabetes

\section{INTRODUCTION}

\section{Chromium and Type 2 Diabetes}

The relationship between chromium intake and glucose metabolism was first reported in the 1950s, when chromium-containing brewer's yeast was reported to prevent diabetes in laboratory animals. ${ }^{1}$ Patients who were deficient in chromium were reported to exhibit symptoms or complications of type 2 diabetes (e.g., peripheral neuropathy, impaired glucose removal, and elevated plasma

Drs. Trumbo and Ellwood are with the Division of Nutrition Programs and Labeling, US Food and Drug Administration, College Park, Maryland.

Please address all correspondence to: Paula R. Trumbo, HFS-830, 5100 Paint Branch Parkway, College Park, MD 20740; Phone: 301-436-2579; Fax: 301-436-2636; E-mail: Paula.Trumbo@FDA.gov. free fatty acids). ${ }^{2-4}$ The provision of chromium to these patients eliminated the symptoms and complications. While chromium's metabolic role in glucose metabolism is not fully understood, it has been hypothesized that it serves as a cofactor for insulin action. ${ }^{5}$

\section{Health Claims}

The Nutrition Labeling and Education Act (NLEA) of 1990 authorized the US Food and Drug Administration (FDA) to allow statements on conventional foods and dietary supplements that describe the relationship between a substance (food or food component) and a disease (e.g., coronary heart disease, cancer, or type 2 diabetes) or healthrelated condition. This relationship is called a health claim. A health-related condition (e.g., hypertension) is a condition that is essentially indistinguishable from a disease (e.g., coronary heart disease) and/or is a surrogate marker for risk of a specific disease (e.g., serum cholesterol levels for coronary heart disease). Health claims were first authorized under the significant scientific agreement (SSA) standard, a rigorous standard that requires a high level of confidence in the validity of a substance-disease relationship. ${ }^{6}$ Due to court decisions dealing with health claims for dietary supplements that raised First Amendment issues, and a major initiative introduced by FDA in 2003, qualified health claims were established for the labeling of conventional foods and dietary supplements. ${ }^{7}$ When credible evidence falls short of the SSA standard, then health claims with qualifying language about the level of scientific evidence (qualified health claims) are issued through letters of enforcement discretion. ${ }^{7}$ SSA and qualified health claims pertain to disease risk reduction in the US population or a target subgroup (e.g., women or the elderly) who do not have the disease that is the subject of the claim.

\section{Evidence-Based Review of Health Claims}

A thorough review of the scientific evidence is a key part of the process for evaluating an SSA or qualified health claim. FDA reviews studies that must be submit- 
ted in petitions seeking a specific health claim. Through a literature search, the agency identifies additional studies that are considered to be relevant to the petitioned health claim. The agency separates individual reports of human studies from other types of data and information. FDA focuses its review on reports of human intervention and observational studies. ${ }^{7}$ In addition to individual reports of human studies, the agency also considers other types of data and information in its review, such as meta-analyses, review articles, and animal and in vitro studies. These other types of data and information can be useful in assisting the agency in understanding the scientific issues about the substance, the disease or healthrelated condition, or both, but cannot by themselves support a health claim relationship.

FDA evaluates the individual reports of human studies to determine whether any scientific conclusions can be drawn from each study. The absence of critical factors such as a control group or a statistical analysis means that scientific conclusions cannot be drawn from the study. ${ }^{8,9}$ Studies from which FDA cannot draw any scientific conclusions about the health claim relationship are eliminated from further review.

Health claims involve reducing the risk of a disease in people who do not already have the disease that is the subject of the claim. Therefore, FDA considers evidence from studies in individuals diagnosed with the disease that is the subject of the health claim only if it is scientifically appropriate to extrapolate to individuals who do not have the disease.

FDA rates the relevant human intervention and observational studies for methodological quality. ${ }^{7}$ This quality rating is based on several criteria related to study design (e.g., use of a placebo-controlled versus a nonplacebo-controlled group), data collection (e.g., type of dietary assessment method), the quality of the statistical analysis, the type of outcome measured (e.g., disease incidence versus validated surrogate endpoint), and study population characteristics other than relevance to the US population (e.g., selection bias and whether important information about the study subjects such as age or smoking status was gathered and reported).

Finally, FDA evaluates the findings of the remaining studies. The agency then ranks the strength of the total body of publicly available evidence. The agency conducts this ranking evaluation by considering the study type (e.g., intervention, prospective cohort, case-control, cross-sectional), the methodological quality rating assigned, the quantity of evidence (number of the various types of studies and sample sizes), whether the body of scientific evidence supports a health claim relationship for the US population or target subgroup, whether study results supporting the proposed claim have been replicated, and the overall consistency of the total body of evidence. ${ }^{7}$ Based on the totality of the scientific evidence, FDA determines whether such evidence is credible to support the substance/disease relationship, and if it is, either authorizes an SSA health claim or issues, through a letter of enforcement discretion, a qualified health claim that reflects the level of scientific evidence.

\section{SURROGATE ENDPOINTS FOR TYPE 2 DIABETES}

FDA uses surrogate endpoints that have been identified by the National Institutes of Health and FDA's Center for Drug Evaluation and Research as validated biomarkers for predicting the risk of a disease. Blood glucose concentration (fasting blood sugar and oral glucose tolerance) and insulin resistance are identified as surrogate endpoints for risk of type 2 diabetes. Insulin resistance is assessed by various measurements of insulin sensitivity, including the glycemic clamp method, homeostasis model assessment, and the fasting insulin/ glucose ratio.

\section{EVALUATION OF INTERVENTION STUDIES}

\section{Chromium Picolinate and Insulin Resistance}

There have been five studies evaluating the effect of chromium picolinate supplementation on the risk of insulin resistance. ${ }^{10-14}$ Two of these studies were conducted in individuals already diagnosed with diabetes. ${ }^{10,11}$ FDA considers evidence from studies in individuals already diagnosed with diabetes only if it is scientifically appropriate to extrapolate to individuals who do not have the disease. Because the mechanism(s) by which chromium may affect glucose metabolism and/or insulin response is hypothetical, ${ }^{5}$ it is not known whether results from studies on the treatment of diabetes with chromium picolinate can be extrapolated to risk reduction of insulin resistance in individuals without diabetes. Therefore, the agency could not draw any scientific conclusions from these two studies about the role of chromium picolinate in reducing the risk of insulin resistance.

Gunton et al. ${ }^{12}$ and Amato et al. ${ }^{13}$ did not conduct statistical analysis between the control and chromium picolinate group. Statistical analysis between the two groups is a critical factor because it provides the comparison between subjects consuming chromium picolinate and those not consuming chromium picolinate to determine whether there is a reduction in risk of insulin resistance. ${ }^{9}$ When statistical analyses are not performed on the specific substance/disease relationship, it cannot be determined whether there is a difference between the two groups. As a result, these studies provided no infor- 
mation about how chromium picolinate may reduce the risk of insulin resistance, and therefore no scientific conclusions could be drawn from them.

There was one intervention study from which the agency could draw scientific conclusions about the relationship between chromium picolinate intake and reduced risk of insulin resistance. Cefalu et al. ${ }^{14}$ was a double-blind, randomized study found to be of moderate methodological quality in which subjects at high risk for diabetes ( $\mathrm{n}=14$ or 15 per group) were provided a placebo or $1000 \mathrm{mg} / \mathrm{d}$ of chromium picolinate for 8 months. Insulin resistance was evaluated by measuring insulin sensitivity. Compared with the control group, there was a significant increase in insulin sensitivity, and therefore reduced insulin resistance, for subjects who took the chromium picolinate supplement.

Because there are other forms of chromium that are present in conventional foods and supplements (e.g., chromium chloride, chromium nicotinamide, yeast), the agency reviewed studies that evaluated the relationship between other forms of chromium and type 2 diabetes. There were five studies measuring the effect of other forms of chromium on risk of insulin resistance. ${ }^{15-19}$ One study did not include a control group for evaluating the relative effect of chromium, ${ }^{17}$ and therefore it could not be determined whether changes in the endpoint of interest were due to chromium or to unrelated and uncontrolled extraneous factors. One study used diabetic patients. ${ }^{19}$ Two studies did not conduct statistical analyses between the control and chromium group. ${ }^{15,16}$ Therefore, scientific conclusions could not be drawn from four of the five studies.

One study was identified in which chromium chloride was provided to healthy subjects to evaluate its effectiveness on reducing the risk of insulin resistance. ${ }^{18}$ This study was found to be of moderate methodological quality and did not show a statistically significant beneficial effect of chromium chloride supplementation on measures of insulin resistance.

\section{Chromium Picolinate and Blood Sugar Concentration}

FDA identified 13 studies evaluating the effect of chromium picolinate supplementation on blood glucose concentrations. ${ }^{12,14,20-30}$ Eight of these studies were not further reviewed because scientific conclusions could not be drawn from them for the following reasons. Walker et al. ${ }^{20}$ did not provide the data within the report; therefore, the agency was not able to evaluate the reliability or the statistical interpretation of the data. In three of the studies, the subjects were already diagnosed with diabetes. $^{21-23}$ Two studies did not include a control group. ${ }^{24-25}$ Statistical analyses were not conducted between the chromium picolinate and control group in two studies. ${ }^{12,26}$

Volpe et al. ${ }^{27}$ conducted a 12-week, randomized study that provided obese US women ( $n=22$ per group) $400 \mathrm{mg} / \mathrm{d}$ of chromium as chromium picolinate. This study was found to be of moderate methodological quality. There was no statistically significant difference in fasting blood sugar (FBS) or oral glucose tolerance test (OGTT) between the chromium picolinate and the placebo group.

Boyd et al. ${ }^{28}$ was a 13 -week, non-randomized study in which healthy US men and women ( $n=9$ per group) were given either a placebo or $1 \mathrm{~g} / \mathrm{d}$ chromium picolinate. This study was found to be of moderate methodological quality. There was no statistically significant beneficial effect of chromium picolinate on FBS or OGTT compared with the placebo control group.

A 12-week, randomized study by Joseph et al. ${ }^{29}$ was conducted on US men and women who were healthy or had glucose intolerance. This study was found to be of moderate methodological quality. Subjects $(n=15$ or 17 per group) received either a placebo or $924 \mathrm{mg} / \mathrm{d}$ of chromium as chromium picolinate and underwent resistance training twice weekly. There was no statistically significant beneficial effect of chromium picolinate on FBS compared with the control group.

Frauchiger et al. ${ }^{30}$ was a single-dose, crossover design study in which young Swiss men $(n=13$ per group) were provided a placebo or 400 or $800 \mathrm{mg}$ of chromium as chromium picolinate 30 minutes prior to the consumption of a test meal. This study was found to be of moderate methodological quality. There was no statistically significant beneficial effect $(P<0.05)$ in OGTT when either 400 or $800 \mathrm{mg}$ of chromium picolinate was consumed.

Cefalu et al. ${ }^{14}$ was a double-blind, randomized study in which subjects at high risk for diabetes $(n=14$ to 15 per group) were provided a placebo or $1000 \mathrm{mg} / \mathrm{d}$ of chromium picolinate for 8 months. There was no statistically beneficial effect of chromium picolinate on OGTT compared with the control group.

FDA identified 29 studies evaluating the effect of other forms of chromium on blood sugar levels. ${ }^{15-18,25,31-51}$ Four of these studies did not include a control group for comparing the relative effect of chromium. ${ }^{17,31-33}$ Nine studies did not conduct statistical analyses between the control and chromium group. ${ }^{15,16,34-40}$ One study was conducted on hypoglycemic patients to determine if chromium chloride had an effect on blood glucose levels. ${ }^{41}$ The purpose of that study, however, was to determine if chromium chloride would increase low blood glucose to normal levels, and therefore it did not address the proposed claim for a reduction in risk of elevated blood glucose levels. Three 





studies were conducted in malnourished children in Jordan, Turkey, and Egypt. ${ }^{42-44}$ Nutrient status and metabolism can be severely altered when an individual is malnourished. For example, malnutrition can result in lower blood glucose and insulin levels, ${ }^{45}$ and therefore the effect of a nutrient, such as chromium, on blood sugar levels can be very different than the effect of the same nutrient on healthy, well-nourished individuals. Thus, scientific conclusions about the effect of other forms of chromium on blood sugar levels in the general US population could not be drawn from these 17 studies.

There have been 11 studies on healthy subjects, ${ }^{18,25,46-54}$ one study on individuals with glucose intolerance, ${ }^{49}$ and one study on both healthy subjects and those with hyperglycemia ${ }^{48}$ that evaluated the effect of other forms of chromium (chromium chloride and chromium nicotinate) on blood glucose levels. These studies were found to be of moderate to high methodological quality. None of the 12 studies in healthy subjects showed a significant beneficial effect of chromium supplementation on FBS and/or OGTT. The two studies in individuals with glucose intolerance showed no significant beneficial effect of chromium supplementation on FBS. ${ }^{49,55}$ One of the two studies showed a statistically significant benefit for OGTT over a 4-hour period in hyperglycemic individuals. ${ }^{48}$

\section{Chromium Picolinate and Type 2 Diabetes}

No studies were identified by FDA that evaluated the effect of chromium picolinate supplementation on the incidence of type 2 diabetes. Thus, the only evidence to support a relationship between chromium picolinate intake and risk of type 2 diabetes are the studies discussed above that measured the effect of chromium picolinate intake on two surrogate endpoints: insulin resistance and blood sugar levels.

\section{EVALUATION OF OBSERVATIONAL STUDIES}

There have been no observational studies evaluating the relationship between the intake of chromium picolinate or other forms of chromium and risk of type 2 diabetes.

\section{SUMMARY}

In summary (Table 1), there was one intervention study that showed a beneficial effect of chromium picolinate intake on risk of insulin resistance. ${ }^{14}$ One other intervention study that provided chromium chloride showed no beneficial effect on insulin resistance. ${ }^{14}$ None of the five intervention studies showed a statistically significant beneficial effect of chromium picolinate on
FBS and/or OGTT. ${ }^{14,23-26}$ Furthermore, none of the 10 intervention studies using other forms of chromium showed a beneficial effect of on FBS or OGTT in individuals with normal glucose tolerance. ${ }^{18,25,46,47,50-54}$

Based on FDA's evidence-based review, the agency concluded that there is very limited credible evidence for a qualified health claim for chromium picolinate and reduced risk of insulin resistance, and therefore reduced risk of type 2 diabetes. The findings of Cefalu et al. ${ }^{14}$ have not been replicated, and replication of scientific findings is important to substantiate results. ${ }^{56}$ For these reasons, FDA concluded that the existence of a relationship between chromium picolinate intake and reduced risk of either insulin resistance or type 2 diabetes is highly uncertain.

On August 25, 2005, FDA issued a letter of enforcement discretion for the labeling of dietary supplements with the following qualified health claim: "One small study suggests that chromium picolinate may reduce the risk of insulin resistance, and therefore possibly may reduce the risk of type 2 diabetes. FDA concludes, however, that the existence of such a relationship between chromium picolinate and either insulin resistance or type 2 diabetes is highly uncertain." 57 The agency concluded that there was no credible evidence to suggest that chromium picolinate intake may reduce the risk of elevated blood glucose levels.

\section{REFERENCES}

1. Schwarz K, Mertz W. Chromium (III) and the glucose tolerance factor. Arch Biochem Biophys. 1959;85: 292-295.

2. Brown RO, Forloines-Lynn S, Cross RE, Heizer WD. Chromium deficiency after long-term parenteral nutrition. Dig Dis Sci. 1986;31:661-664.

3. Freund H, Atamian S, Fischer JE. Chromium deficiency during parenteral nutrition. JAMA. 1979;241: 496-498.

4. Jeejeebhoy KN, Chu RC, Marliss EB, Greenberg GR, Bruce-Robertson A. Chromium deficiency, glucose intolerance, and neuropathy reversed by chromium supplementation in a patient receiving longterm total parenteral nutrition. Am J Clin Nutr. 1977; 30:531-538.

5. Vincent JB. Quest for the molecular mechanism of chromium action and its relationship to diabetes. Nutr Rev. 2000;58:67-72.

6. US Food and Drug Administration, Center for Food Safety and Applied Nutrition, Office of Special Nutritionals. Guidance for Industry Significant Scientific Agreement in the Review of Health Claims for Conventional Foods and Dietary Supplements. Available at: http://www.cfsan.fda.gov/ dms/ssaguide.html. Accessed July 12, 2006.

7. US Food and Drug Administration, Center for Food Safety and Applied Nutrition. Consumer Health Information for Better Nutrition Initiative. Task Force Final Report. Available at: http://www.cfsan.fda. gov/ dms/nuttftoc.html. Accessed July 12, 2006. 
8. US Courts, Federal Judicial Center. Reference Manual on Scientific Evidence. 2nd ed. Washington, DC: US Government Printing Office; 2000; 93.

9. Spilker B. Guide to Clinical Studies. New York: Raven Press; 1991.

10. Morris BW, S Kouta, R Robinson S, MacNeil S, Heller S. Chromium supplementation improves insulin resistance in patients with type 2 diabetes mellitus. Diabet Med. 2000;17:684-685.

11. Ravina A, Slezak L, Rubal A, Mirsky N. Clinical use of the trace element chromium (III) in the treatment of diabetes mellitus. J Trace Elem Med Biol. 1995; 8:183-190.

12. Gunton JE, Cheung NW, Hitchman R, et al. Chromium supplementation does not improve glucose tolerance, insulin sensitivity or lipid profile. Diabetes Care. 2005;28:712-713.

13. Amato P, Morales AJ, Yen SS. Effects of chromium picolinate supplementation on insulin sensitivity, serum lipids, and body composition in healthy, nonobese, older men and women. J Gerontol A Biol Sci Med Sci. 2000;55:M260-M263.

14. Cefalu WT, Bell-Farrow AD, Stegner J, et al. Effect of chromium picolinate on insulin sensitivity in vivo. J Trace Elem Exp Med. 1999;12:71-83.

15. Offenbacher EG, Rinko CJ, Pi-Sunyer FX. The effects of inorganic chromium and brewer's yeast on glucose tolerance, plasma lipids, and plasma chromium in elderly subjects. Diabetes. 1985;29:919925.

16. Riales R, Albrink MJ. Effect of chromium chloride supplementation on glucose tolerance and serum lipids including high-density lipoprotein of adult men. Am J Clin Nutr. 1981;34:2670-2678.

17. Potter JF, Levin P, Anderson RA, Freiberg JM, Andres R, Elahi D. Glucose metabolism in glucoseintolerant older people during chromium supplementation. Metabolism. 1985;34:199-204.

18. Wang M, Fox E, Stoecker B, Menendez C, Chan SB. Serum cholesterol of adults supplemented with brewer's yeast of chromium chloride. Nutr Res. 1989;9:989-998.

19. Elias AN, Grossman MK, Valenta, LJ. Use of the artificial beta cell (ABC) in the assessment of peripheral insulin sensitivity: effect of chromium supplementation in diabetic patients. General Pharmacol. 1984;15:535-539.

20. Walker LS, Bemben MG, Bemben DA, Knehans AW. Chromium picolinate effects on body composition and muscular performance in wrestlers. Med Sci Sports Exerc. 1998;30:1730-1737.

21. Ravina A, Slezak L, Mirsky N, Bryden NA, Anderson RA. Reversal of corticosteroid-induced diabetes mellitus with supplemental chromium. Diabetes Med. 1999;16:164-167.

22. Jovanovic-Peterson L, Gutierrez M, Peterson CM. Chromium supplementation for women with gestational diabetes mellitus. J Trace Elem Med Biol. 1999;12:91-97.

23. Cheng N, Zhu X, Hongli S, Wo W, Chi J, Cheng J, Anderson R. Follow-up survey of people in China with type 2 diabetes mellitus consuming supplemental chromium. J Trace Elem Med Biol. 1999;12: 55-60.

24. Kato I, Vogelman JH, Dilman V, et al. Effect of supplementation with chromium picolinate on antibody titers to 5-hydroxymethyl uracil. Eur $\mathrm{J}$ Epidemiol. 1998;14:621-626.

25. Grant KE, Chandler RM, Castle AL, Ivy JL. Chromium and exercise training: effect on obese women. Med Sci Sports Exerc. 1997;29:992-998.

26. Pasman WJ, Westerterp-Plantenga MS, Saris WH. The effectiveness of long-term supplementation of carbohydrate, chromium, fibre, and caffeine on weight maintenance. Int $\mathrm{J}$ Obstet Relat Metab Disord. 1997;21:1143-1151.

27. Volpe SL, Huang HW, Larpadosorn K, Lester I. Effect of chromium supplementation and exercise on body composition, resting metabolic rate and selected biochemical parameters in moderately obese women following an exercise program. J Am Coll Nutr. 2001;20:293-306.

28. Boyd GS, Boone BE, Smith AR, Conners J, Dohm GL. Combined dietary chromium picolinate supplementation and an exercise program leads to a reduction of serum cholesterol and insulin in collegeaged subjects. J Nutr Biochem. 1998;9:471-475.

29. Joseph LJ, Farrell PA, Davey SL, Evans WJ, Campbell WW. Effect of resistance training with or without chromium picolinate supplementation on glucose metabolism in older men and women. Metabolism. 1999;48:546-553.

30. Frauchiger MT, Caspar W, Colombani PC. Effects of acute chromium supplementation on postprandial metabolism in healthy young men. J Am Coll Nutr. 2004;23:351-357.

31. Liu VJ, Morris JS. Relative chromium response as an indicator of chromium status. Am J Clin Nutr. 1978;31:972-976.

32. Vinson JA, Bose $P$. The effect of high chromium yeast on blood glucose control and blood lipids of normal and diabetic human subjects. Nutr Rep Inter. 1984;30:911-918.

33. Glinsmann WH, Mertz W. Effect of trivalent chromium on glucose tolerance. Metabolism. 1966;15: 510-520.

34. Martinez OB, MacDonald AC, Gibson RS. Dietary chromium and effect of chromium supplementation on glucose tolerance of elderly Canadian women. Nutr Res. 1985;5:609-620.

35. Li YC, Shin SJ, Chen JC. Effects of brewer's yeast and torula yeast on glucose tolerance, serum lipids and chromium contents in adult human beings. J Chin Nutr Soc. 1992;17:147-155.

36. Offenbacher EG, Pi-Sunyer FX. Beneficial effect of chromium-rich yeast on glucose tolerance and blood lipids in elderly subjects. Diabetes. 1980;29: 919-925.

37. Urberg M, Zemel MB. Evidence for synergism between chromium and nicotinic acid in the control of glucose tolerance in elderly humans. Metabolism. 1987;36:896-899.

38. Gill TP, Wahlqvist ML, Flint DM. The effects of short-term chromium supplementation on insulin response to a glucose load in healthy subjects. Proc Nutr Soc Australia. 1981;6:98.

39. Sherman L, Glennon JA, Brech WJ, Klomberg GH, Gordon ES. Failure of trivalent chromium to improve hyperglycemia in diabetes mellitus. Metabolism. 1968;17:439-442. 
40. Crawford V, Scheckenbach R, Preuss HG. Effects of niacin-bound chromium supplementation on body composition in overweight African-American women. Diabetes Obes Metab. 1999;1:331-337.

41. Anderson RA, Polansky MM, Bryden NA, Bhathena SJ, Canary JJ. Effects of supplemental chromium on patients with symptoms reactive hypoglycemia. Metabolism. 1987;36:351-355.

42. Gurson CT, Saner G. Effect of chromium on glucose utilization in marasmic protein-calorie malnutrition. Am J Clin Nutr. 1971;24:1313-1319.

43. Carter JP, Kattab A, Abd-el-Hadi K, Davis JT, el Gholmy A, Patwardhan VN. Chromium (3) in hypoglycemia and in impaired glucose utilization in kwashiorkor. Am J Clin Nutr. 1968;21:195-202.

44. Hopkins LL, Ransome-Kuti O, Majaj AS. Improvement of impaired carbohydrate metabolism by chromium 3 in malnourished infants. Am J Clin Nutr. 1968;21:203-211.

45. Torun B, Chew F. Protein-energy malnutrition. In: Shils ME, Olson JA, Shike M, Ross AC, eds. Modern Nutrition in Health and Disease. Baltimore, MD: Williams \& Wilkins; 1999; 936-988.

46. Lefavi R, Wilson D, Keith R, Anderson R, Blessing D, Hames C, McMillian J. Lipid-lowering effect of a dietary chromium (III) nicotinic acid complex in male athletes. Nutr Res. 1993;13:239-249.

47. Li YC. Effects of brewer's yeast on glucose tolerance and serum lipids in Chinese adults. Biol Trace Elem Res. 1994;41:341-347.

48. Anderson RA, Polansky MM, Bryden NA, Canary JJ. Supplemental-chromium effects on glucose, insulin, glucagons, and urinary chromium losses in subjects consuming controlled low-chromium diets. Am J Clin Nutr. 1991;54:909-916.

49. Hermann J, Chung H, Arquitt A, Goad C, Burns M, Chan B. Effects of chromium or copper supplemen- tation on plasma lipids, plasma glucose and serum insulin in adults over age fifty. J Nutr Elderly. 1998; 18:27-45.

50. Anderson RA, Polansky MM, Bryden NA, Roginski EE, Mertz W, Glinsmann W. Chromium supplementation of human subjects: effects on glucose, insulin, and lipid variables. Metabolism. 1983;32:894899.

51. Hermann J, Arquitt A, Stoecker B. Effects of chromium supplementation on plasma lipids, apoproteins, and glucose in elderly. Nutr Res. 1994;14: 671-674.

52. Thomas VL, Gropper SS. Effect of chromium nicotinic acid supplementation on selected cardiovascular disease risk factors. Biol Trace Elem Res. 1996;55:297-305.

53. Uusitupa M, Mykkanen L, Siitonen O, et al. Chromium supplementation in impaired glucose tolerance of elderly:effects of blood glucose, plasma insulin, C-peptide and lipid levels. Br J Nutr. 1992; 68:209-216.

54. Wilson BE, Gondy A. Effects of chromium supplementation on fasting insulin levels and lipid parameters in healthy, non-obese young subjects. Diabetes Res Clin Prac. 1995;28:179-184.

55. Abraham AS, Brooks BA, Eylath U. The effects of chromium supplementation on serum glucose and lipids in patients with and without non-insulin-dependent diabetes. Metabolism. 1992;41:768-771.

56. Wilson EB. An Introduction to Scientific Research. New York:Dover Publishing; 1990; 46-48.

57. US Food and Drug Administration, Center for Food Safety and Applied Nutrition. Qualified Health Claims: Letter of Enforcement Discretion Chromium Picolinate and Insulin Resistance. Available at: http://www.cfsan.fda.gov/ dms/qhccr. html. Accessed July 12, 2006. 